\title{
Overview
}

\section{Styles of Parenting}

\section{Barbara A. Hotelling, BSN, CD(DONA), LCCE, FACCE}

BARBARA HOTELLING is an independent childbirth educator and doula in Rochester Hills, Michigan. She currently serves as president of Lamaze International and as a faculty member of Lamaze. She has also served as president of Doulas of North America (DONA) and chair of the Coalition for Improving Maternity Services (CIMS).

\begin{abstract}
In this brief overview, the author contrasts two current parenting styles: Attachment Parenting and Babywise Parenting.

Journal of Perinatal Education, 13(1), 42-44; parenting, infant care.
\end{abstract}

Not all parenting styles are alike. What individuals do as parents depends somewhat on how they were raised as a child, what they observed in other families, and what they have been taught. Two very different styles have emerged: Attachment Parenting and Babywise Parenting (see the following table for an overview of each style). One's own developed style of parenting will probably fall somewhere between the two.

Attachment Parenting is a highly respected approach that promotes securely attached children. The problems with Babywise Parenting, however, have been known to include detachment, behavioral disorders, dehydration, failure to thrive, irritability, infant anorexia, and even infant death.

Parenting is never easy. Perspective parents are encouraged to seek out resources for support and information, starting now, to help ease the way. One thing is for sure: No recipe for parenting will guarantee a good night's sleep every night or perfect children.

(continued on next page) 


\section{Attachment Parenting (from Attachment Parenting International www.attachmentparenting.org)}

Theory

Attachment Parenting is a style of parenting that develops an infant or child's need for trust, empathy, and affection in order to create a secure, peaceful, and enduring relationship. This style requires a consistent, loving, and responsive caregiver, ideally a parent, especially during the child's critical first 3-5 years of life. Preparation for
Childbirth

Emotional Responsiveness

Feeding

Baby Wearing

Sleep
The best way to start becoming connected with your baby is to be informed and active in your baby's birth. You can make informed decisions about the kind of birth you want that will create a positive experience for you and your baby and limit unnecessary separations.

Being emotionally responsive to your baby's emotional needs is the cornerstone to Attachment Parenting. Read and respond sensitively to your baby's cues and signals. Remember that crying is your baby's way of telling you s/he is distressed. Listen to those cries and try to respond before your baby has a need to cry. Connect with your baby early on. Connecting is more than just caring for the baby's physical needs; it also involves spending enjoyable time interacting with your baby or child.

Breastfeeding your baby is an easy way to meet your baby's need for food, liquids, and physical contact. Breastfeeding has so many benefits to the baby, mother, and our society and is the most natural way to meet so many of your baby's physical needs.

Young babies have a need for a lot of physical contact with you. "Wearing" your baby-that is, holding the infant or using baby slings or soft carriers-is a wonderful way to meet your baby's need for close physical contact. Carried babies cry less, too.

In many cultures, it is considered normal and expected for parents to sleep with their children. Only recently has research shown the benefits for babies (e.g., a reduced risk of SIDS). Attachment Parenting advocates safe bed sharing in which the parents are not using drugs or alcohol and have a safe, firm mattress. Although some parents may not be comfortable with the idea of bed sharing, the key is merely being responsive to the child's nighttime needs.

\section{Babywise Parenting (from On Becoming Babywise by Garry Ezzo and Robert Bucknam, MD)*}

Babywise Parenting claims that parents can establish a routine in their baby's life from day one and stick to it no matter what. Parent-Directed Feeding (PDF) is an infant-management strategy designed to meet the nutritional, physical, and emotional needs of the baby as well as the needs of the whole family (p. 38). Two related dangers threaten successful parenting: not understanding the significance of the husband-wife relationship in the parenting process and the hazard of child-centered parenting (p. 19).

No Comments

Babies become not only conditioned to being picked up at a whimper but also abnormally dependent on being picked up (p. 38).

PDF is made up of three basic activities that are repeated in a rhythmical cycle throughout the day: feeding time, waketime, and naptime. These cycles are both routine and predictable (p. 42).

If your baby does not eat at a scheduled feeding, s/he must wait until the next one. Feedings are at $21 / 2$ to 3-hour intervals. Your baby's routine is to serve you; you are not to serve your baby's routine ( $\mathrm{p}$. 132).

You can hurt a baby by picking him or her up too much (p. 128).

Naps are not an option based on your baby's wants. When naptime comes, the baby goes down in the crib (p. 118). Crying for $15-20$ or even 30 minutes is not going to hurt your baby, physically or emotionally (p. 118).

The three most common negative sleep props are 1) intentionally nursing a baby to sleep, 2) rocking a baby to sleep, and 3) sleeping with the baby. (p. 57). 


\section{Overview: Styles of Parenting}

(continued)

\author{
Attachment Parenting (from \\ Attachment Parenting International \\ www.attachmentparenting.org)
}

Separation

Avoid frequent and prolonged separations from your baby. Secure attachments can be damaged by lengthy separations between the parent and young child. Keep separations down to a bare minimum when your baby is young and be responsive to your baby's need for your physical presence. Long separations can cause your child to go through the stages of grief and can affect your child's attachment to you. If separations are inevitable, then help your child to gradually work toward them. The ideal situation is continuity of care and having a consistent, loving caregiver.

Discipline

Set limits for your baby or young child in a warm, loving manner. Teach empathy through positive, nonviolent methods of discipline. (Ideally, the loving connection and responsiveness established during infancy should continue throughout childhood. Attachment Parenting International's book list contains excellent materials for group discussion on parenting the older child as well as an infant.)

\section{Babywise Parenting (from On Becoming Babywise by Garry Ezzo and Robert Bucknam, MD)*}

The nature of the PDF program fosters relational security. That is, a baby's security depends on her developing relationship, not on proximity to the baby's mother. In contrast, mothers who are constantly attentive by the way of baby slings, shared sleep, and demand feeding, all in hopes of fostering security, too often accomplish the opposite (p. 46).

The authors of On Becoming Babywise assume the reader is family-centered, not child-centered. Parents regard their baby as a welcome member of the family, though not the center of the family universe (p. 16). No evidence proves that an immediate response to every cry teaches a baby anything about love, just as no evidence proves that a little crying fosters feelings of insecurity (pp. 126-127).

* Ezzo, G., \& Bucknam, R. (1995). On becoming babywise. Sisters, OR: Multnomah Books. Compiled by Barbara A. Hotelling, BSN, CD(DONA), LCCE, FACCE, from On Becoming Babywise by Garry Ezzo and Robert Bucknam, MD, and with permission from Attachment Parenting International (www.attachmentparenting.org).

\section{Thoughts on Parenting}

A concern with parenting...must direct attention beyond behavior. This is because parenting is not simply a set of behaviors, but participation in an interpersonal, diffuse, affective relationship. Parenting is an eminently psychological role in a way that many other roles and activities are not.

in The Reproduction of Mothering: Psychoanalysis and the Sociology of Gender (1978)

Parenting forces us to get to know ourselves better than we ever might have imagined we could-and in many new ways.... We'll discover talents we never dreamed we had and fervently wish for others at moments we feel we desperately need them. As time goes on, we'll probably discover that we have more to give and can give more than we ever imagined. But we'll also find that there are limits to our giving, and that may be hard for us to accept.

-Fred Rogers

in Mister Rogers Talks with Parents (1983)

This [new] period of parenting is an intense one. Never will we know such responsibility, such productive and hard work, such potential for isolation in the caretaking role, and such intimacy and close involvement in the growth and development of another human being.

- Joan Sheingold Ditzion and Dennie Palmer

in Ourselves and Our Children by Boston Women's Health Book Collective (1978) 